\title{
The Progress on Real Options for Company Valuation
}

\author{
Yixuan Chen ${ }^{1, *}$ \\ ${ }^{1}$ Mathematics Department, University of Waterloo, N2L 3G1, Waterloo, Canada
${ }^{*}$ Corresponding author. Email: y2497che@ uwaterloo.ca
}

ABSTRACT

Nowadays, real options derived from financial options are increasingly used in asset pricing. However, with different business models varied by companies, the existing real option pricing models are unable to be generally adopted. This paper addresses the problem of asset pricing under the impact of potential factors and discusses the path to carry out fair asset pricing with various business models. For the purpose of exploring the pricing method of using real options for asset pricing in practice, the article researches and sorts out the existing literature based on information retrieval. The applicability of real options, real options pricing models, parameter estimations, and the difficulties and problems during the application are systematically analyzed. Subsequently, the future research outlook and guideline are proposed.

These results shed light for a more accurate and practical company valuation provided by real option pricing methodology compared with the DCF method

Keywords: Real option method, BS model, Asset pricing

\section{INTRODUCTION}

The decision-making issue that companies often face in their business activities is whether they should carry out a project with a large investment. For example, one often sees private placements in the capital market and additional issuance funds are often used as the start-up capital of an investment project. However, strategic investment project often requires a long payback period. These investments often fail to bring timely returns or even direct returns. Instead, they create potential investment opportunities by improving the company's internal organizational capabilities.

Due to the characteristics of the company's investment projects as mentioned above, it is relatively difficult for the traditional Discounted Cash Flow method (DCF) to accurately estimate the value of the project. Myers [1] believes that the traditional NPV method cannot accurately calculate the present value of an asset or project, since a large proportion of its value comes from the present value of future options. Such options are called real options. According to different execution time and directions, real options can be divided into delay options, growth options, abandon options, and contraction options. If one still uses the traditional NPV method to analyze the project when one or more options exist, the option values will be ignored, i.e., may underestimate the overall value of the project. This leads to the problem of insufficient investment. Similar to insufficient investment in Research and Development caused by the negligence of the company's informatization construction, it will hurt the competitiveness of the company in the long run. The real option method takes future option values into consideration and provides a more accurate estimate for current investment decisions. Therefore, real options have received more attention and have been into widely applied within a project decision-making methodology.

Options have time and intrinsic values, which is why they must be fairly measured in actual decision-making procedures. In fact, the core issue of all economic decisions is how to set fair prices that corresponds to their values. Making reasonable estimates for all relevant economic factors, and then making investment decisions based on a more fair, objective, and accurate judgment, has become the key to the success of the decision. Option pricing theory comes from the valuation of financial options, but the main idea is to accurately measure the value of uncertainty to reduce costs. Since uncertainty is an inevitable factor in all economic decisions, the valuation method of financial options can also be adopted in the valuation of real options. Therefore, the difficult problem is the suitable way to use financial option valuation methods to value real option financial valuation. 
This article reviews the research progress of using the real option method to evaluate the project and reveals the development status of real options. Section 2 reviews the concept, source, and significance of the real option method; Section 3 explores the advantages of real options over the DCF valuation method through relevant academic researches; Section 4 summarizes the relevant model of applying real options to project valuation: the binary tree model, the trigeminal tree model, the Black Scholes model, the Geske model, stochastic differential equation method, and the Monte Carlo simulation method; Section 5 discusses the estimation of the specific parameters used in the real option model, and analyzes the value of the underlying asset, the execution price, the exercise period, the volatility, and the valuation method of the risk rate; Section 6 then discusses the difficulties and problems in the application of real options; Section 7 puts forward relevant prospects for the research direction of real options.

\section{APPLICABILITY OF REAL OPTION APPROACH}

For the research on the applicability of the real option method, scholars have discovered some huge advantages of the real option by comparing the real option with the traditional valuation method.

Banerjee [2] used the real option method to evaluate the value of Indian pharmaceutical companies. Based on the analysis, it was difficult to explain $39 \%$ of the company's market value by using the traditional DCF method to estimate the results. Specifically, for pharmaceutical companies, their market values were mostly driven by technological milestones achieved in research, i.e., the value of intellectual property. These values could not be captured in the DCF model. Zhang, Nieto, and Kleit [3] studied the valuation of mineral companies. They believed that the traditional discounted cash flow method was a more accurate evaluation method when the price of minerals was stable. However, when there were relatively large price fluctuations in mineral prices, companies would change their business decisions since it was difficult for traditional discounted cash flow methods to capture these changes. The research conducted by Sudarsanam, Sorwar, and Marr [4] believed that as for technology companies, values also mainly came from intellectual property rights. For such enterprises, although the DCF method was more complicated and precise, it was difficult for the DCF method to fully consider the contribution from intellectual property in estimating enterprise values. Furthermore, it was impossible to accurately estimate future cash flow, and the discount rate was often incorrectly estimated, because uncertainty was not necessarily a negative sign. Thus, many scholars believed that the application of traditional DCF valuation methods had limitations for various types of companies, e.g., mining companies and technological companies, and reflecting the entire value of the company was challenging.

Compared with the DCF method, the real option is very different. The first is that DCF implies that the greater volatility of future cash flow will reduce the present value of the project. However, from the perspective of real options law, small volatility is not necessarily a bad thing. The greater uncertainty of future cash flows may not yield a greater loss, because the loss is often because of the large sum of initial investment, and the characteristics of real options enable us to choose the part of uncertainty that is beneficial to us. For example, when the conditions are good, one chooses to continue the project or even start a new project. When the conditions are bad, one can choose not to invest or cut off the loss-making projects. In turn, the volatility of cash flow is not unbiased. The second is that the extension of the decision-making time can increase the value of the project, because if there is an unfavorable situation, one can pause the project and wait until the conditions are ripe enough to continue.

Under the real option method, the operator can replicate a portfolio to hedge the risk of the project. In theory, this risk can be completely hedged, i.e., the risk-free interest rate can be used as the discount rate. This is where the real option approach makes the most sense. Under certain circumstances, financial option pricing methods can be used to value physical assets. This article attempts to summarize what problems have been studied and what progress has been made in the existing literature.

\section{VALUATION MODEL}

The Black-Scholes financial option pricing model deduced by Black and Scholes plays a powerful role in promoting the development of later real option pricing models, and has set a precedent for the study of option pricing models. From the perspective of the change in the price of the underlying asset, real options can be classified into two types: discrete and continuous. The current pricing models of discrete options include binary tree and trinomial tree models. The continuous real option pricing models include BS model, Geske model, stochastic differential equation method, Monte Carlo simulation method, etc. We will sort out these methods below.

\subsection{Binary Tree Model and Trinomial Tree Model}

The binary tree model was proposed by Cox, Ross, and Rubinstein [5]. The model assumed that the price of stocks can only rise and fall in a certain period of time. 
One could replicate the investment portfolio with the same cash flow to determine the value of the option.

Later, scholars expanded the binary tree model based on this research and proposed the trinomial tree model. Boyle [6] believed that there were three situations in asset prices at each node: rising, falling and unchanged; further research by Omberg [7] believed that when it was necessary to compare the trinomial higher step change process for multi-step valuation, when the time, the modified Gauss-Hermite process with uniform transition could be used; subsequently, Tian [8] aimed at the two fork tree model and the three fork tree model proposed by Boyle, in which the two parameters of the jump direction and probability were restricted. The selection situation of the model was revised, thereby improving the accuracy of the model.

The formula can be expressed as:

$$
f=\left[p f_{u}+(1-p) f_{d}\right] e^{-r T}
$$

where

$$
p=\frac{e^{r T}-d}{u-d}
$$

The binary tree model was also specifically applied in real economic practice. Sheridan Titman [9] used a binary tree model to evaluate the value of vacant land and proved that future options for land use would play a decisive role in the value of vacant land. Kellogg and Charles [10] found that many companies in the biotechnology industry had very high stock prices despite the fact that their products were in the early development stage and had no product revenue. Therefore, they used the binary tree model to evaluate the value of high-tech enterprises and found that in the early stage of the development of high-tech enterprises, the binary tree model could estimate the value of the company better than the traditional DCF method.

\subsection{BS model and Geske model}

The Black-Scholes model and the Geske model are the most common closed-form equation models. The model uses the method of stochastic differential equations to solve a set of equations and finally obtains a specific analytical solution.

The formula of BS model can be expressed as:

$$
c=S_{0} N\left(d_{1}\right)-K e^{-r T} N\left(d_{2}\right)
$$

where

$$
d_{1}=\frac{\ln \frac{S_{0}}{K}+\left(r+\frac{\sigma^{2}}{2}\right) T}{\sigma \sqrt{T}}
$$

$$
d_{2}=\frac{\ln \frac{S_{0}}{K}+\left(r-\frac{\sigma^{2}}{2}\right) T}{\sigma \sqrt{T}}=d_{1}-\sigma \sqrt{T}
$$

The BS model was a model that Black and Scholes withdrew from the pricing of financial options. In subsequent studies, scholars also used this model in the pricing of real options. This model was also the most widely used. The Geske model was derived from Geske [11] based on the BS model, considering the pricing of compound options at a fixed execution price. Compound options are considered to be options of options. When the company or individual asset under evaluation develops and operates in stages, and there may be different types of real options at different stages, the use of compound options-Geske model can better estimate the target of evaluation. The intrinsic value of it is usually combined with life cycle theory. Similar to the BS model, the Geske model is also based on a series of assumptions. In order to broaden the scope of application of the model, Geske and Johnson [12] derived an American compound option pricing model based on the original Geske model. Besides, Geman [13] derived a compound option pricing model when volatility and risk-free interest rates were dynamically changing.

Regarding the application of the BS model and the Geske model, one can use case analysis to evaluate the value of multi-stage development start-ups. On the basis of the traditional discounted cash flow method, the Geske model is used to calculate the value of the compound option of the company in the start-up phase and the mature phase. Additionally, the sum of the two is used as the overall corporate value of the start-up company.

\subsection{Stochastic differential equation method}

Stochastic differential equation method is a method of constructing bounded stochastic differential equations based on a series of premises and assumptions, and then calculating the value of options through complex mathematical calculations and derivations. The stochastic differential equation method is also the mathematical basis of the BS model and the Geske model.

The formula can be expressed as:

$$
\frac{\partial f}{\partial t}+r S \frac{\partial f}{\partial S}+\frac{1}{2} \sigma^{2} S^{2} \frac{\partial^{2} f}{\partial S^{2}}=r f
$$

If the change in the price of the underlying asset obeys Brownian motion, the BS model is the derivation of this method. In the valuation of real options, there are more assumptions. Since the calculation is complicated, the results of the application of this method are more presented in the form of numerical solutions. 
In practical applications, Schwartsz and Moon [14] used the stochastic differential equation method to evaluate the value of online companies under high income growth rates based on real option theory and capital budgeting theory. Moreover, Ottoo [15] also used this method to evaluate biopharmaceuticals. It showed that the company was a potential and innovative pharmaceutical product value.

\subsection{Monte Carlo simulation method}

Monte Carlo simulation is a kind of estimation method of scene simulation. This method takes the uncertainty of the option's expiration period, execution price, and execution time into account. It assumes the possible price path of the underlying asset from the current to the expiration date, and then conducts scenario simulation. This method first calculates the final value of the underlying asset in each case, then discounts the final value of each path with the risk-free interest rate, and then calculates the weighted average as the value of the real option.

In practical terms, Bolye [16] used Monte Carlo simulation for the first time to price options. He believed that continuous path simulation could improve the accuracy of option value. Longstaff and Schwartsz [17] considered that the traditional Monte Carlo model method was only suitable for European option pricing, and then proposed a least square Monte Carlo simulation method suitable for American options. Furthermore, the applicable scope of the Monte Carlo model method was improved.

\section{PARAMETER ESTIMATION}

As mentioned earlier, the BS pricing model is a commonly used model in real option pricing method. Although real options are derived from financial options and the expressions of the two models are the same, the meanings of the parameters in the models are different. The specific differences are shown in the Table 1.

Table 1. Parameter Interpretation in Financial Options vs in Real Options

\begin{tabular}{|c|c|c|}
\hline & $\begin{array}{l}\text { Financial } \\
\text { Options }\end{array}$ & Real Options \\
\hline $\begin{array}{l}\text { Underlying } \\
\text { asset }\end{array}$ & $\begin{array}{l}\text { Financial } \\
\text { assets such as } \\
\text { stocks }\end{array}$ & $\begin{array}{l}\text { Enterprise or } \\
\text { individual asset }\end{array}$ \\
\hline $\begin{array}{r}\text { Underlying } \\
\text { asset value (S) }\end{array}$ & $\begin{array}{l}\text { Current } \\
\text { price of the } \\
\text { underlying } \\
\text { asset }\end{array}$ & $\begin{array}{l}\text { The underlying } \\
\text { asset does not } \\
\text { contain the value } \\
\text { of the real option }\end{array}$ \\
\hline
\end{tabular}

\begin{tabular}{|c|c|c|}
\hline & & $\begin{array}{c}\text { value on the } \\
\text { evaluation base } \\
\text { date }\end{array}$ \\
\hline $\begin{array}{l}\text { Execution } \\
\text { price }(X)\end{array}$ & $\begin{array}{l}\text { Strike } \\
\text { price of } \\
\text { financial } \\
\text { option }\end{array}$ & $\begin{array}{l}\text { When the } \\
\text { option is } \\
\text { exercised, the } \\
\text { price paid or } \\
\text { compensation for } \\
\text { buying and selling } \\
\text { assets }\end{array}$ \\
\hline $\begin{array}{l}\text { Exercise } \\
\text { period }(T)\end{array}$ & $\begin{array}{l}\text { Validity } \\
\text { period of } \\
\text { financial } \\
\text { options }\end{array}$ & $\begin{array}{c}\text { The time span } \\
\text { between the } \\
\text { evaluation base } \\
\text { date and the time } \\
\text { when the real } \\
\text { option is } \\
\text { exercised }\end{array}$ \\
\hline Volatility $(\sigma)$ & $\begin{array}{c}\text { The } \\
\text { variance of } \\
\text { the } \\
\text { underlying } \\
\text { asset price }\end{array}$ & $\begin{array}{l}\text { Variance of } \\
\text { the expected } \\
\text { return on the } \\
\text { underlying asset }\end{array}$ \\
\hline $\begin{array}{c}\text { Risk-free } \\
\text { interest rate (r) }\end{array}$ & $\begin{array}{l}\text { Treasury } \\
\text { bond interest } \\
\text { rate }\end{array}$ & $\begin{array}{l}\text { Treasury bond } \\
\text { interest rate }\end{array}$ \\
\hline
\end{tabular}

Since there are many types of assets bid in real options, the estimation of parameters in the BS pricing model is more complicated, and the specific estimation methods are different.

\subsection{Estimation of the value (S) of the underlying asset}

In financial options, the price of the underlying asset is directly given, and one can see the dynamic price of the underlying asset of the option. Nevertheless, in real options, this price is often not readily available, i.e., one needs to estimate the value of the underlying asset of the real option.

In financial options, $\mathrm{S}$ refers to the current price of the asset, and similarly, the value of the asset bid in the real option. Generally, it refers to the intrinsic value of the underlying asset after deducting the value of the real option on the evaluation base date. Therefore, one needs to calculate the intrinsic value of the target when estimating the value of the target asset (S). 


\subsection{Estimate of the execution price $(X)$}

In financial options, the strike price $\mathrm{X}$ often refers to the purchase price. Similarly, the strike price in a real option generally refers to the investment cost of the underlying asset. Hall and Murph [18] believed that in equity incentives, the exercise price of an option was often the stock market price on the date of grant of the stock option, so the exercise price was fixed during the validity period of the option. Majewska [19] introduced the exercise price formula and believed that stock options with variable exercise prices had a better incentive effect for management. Similarly, in real options, the underlying assets were different, so the investment costs were different.

\subsection{Estimation of the exercise period $(T)$}

The traditional BS model assumes that the option will only be executed on the expiry date, which belongs to the category of European options. Hence, the exercise period is the time interval from the evaluation base date to the real option exercise date. Nevertheless. like financial options, real options may also be executed early. Considering that the derivation of the BS model comes from the stochastic differential method, one can take this factor into consideration when constructing the stochastic differential equation. By modifying some assumptions about the time parameters in the equation, it is possible to derive the result of the equation with a numerical solution rather than an analytical solution. Otherwise, one can use the binary tree model to solve the issue as it can be applied to both American options and European options.

\subsection{Estimation of volatility $(\sigma)$}

The volatility in a real option is generally the standard deviation of the price or expected return of the asset of the indicator from the evaluation base date to the exercise date. In actual implementation, the volatility of the project value may be impossible to estimate. However, considering that the volatility of the project value and the volatility of the output price have a strong correlation, one can use the volatility of the related product as the approximate volatility of the project. The estimation of volatility should not only consider the reliability and relevance of the estimated results, but also the availability of data required for volatility calculation. Only after comprehensive consideration of many aspects can a more reasonable result be obtained.

\subsection{Estimation of risk-free interest rate $(r)$}

Compared with other parameters, the risk-free interest rate is an easier parameter to estimate in the B-S pricing model. In the pricing process of real options and financial options, based on the no-arbitrage theory, the risk-free national debt interest rate is generally used as the discount rate, which is assumed to be a constant. In early studies, scholars believed that interest rates obey a random distribution from the perspective of the term structure of modern interest rates and used different models to describe the random behavior of interest rates: Black and Scholes [20] introduced the geometric Brownian motion process of interest rates; Vasicek [21] deduced interest rates A discounted bond price equilibrium model that obeys the Ornstein-Uhlenbeck motion process. Afterward, the interest rate distribution behavior is widely used in the value evaluation model of derivative financial instruments such as options, futures and futures options; Cox, Ingersoll and Ross [22] break no arbitrage Theory, introducing a general equilibrium term structure model of order factors in a competitive economy.

\section{DIFFICULTIES AND PROBLEMS IN THE APPLICATION OF REAL OPTIONS METHOD}

Based on literature review, it is revealed that the real option method has been studied extensively in the theoretical circle, but there are still some difficulties and problems that cannot be ignored in the application of this method.

However, this model also has many limitations. The first limitation is that the interest rate of short-term government bonds is often used as the risk-free interest rate, but the interest rate of short-term bonds is not fixed. Secondly, it is relatively difficult to determine the market risk premium, and thirdly, the rate of return required by market risk is uncertain

\subsection{Multiple model assumptions}

Most of the pricing models in the real option method are based on a series of assumptions under ideal conditions. In the actual situation, most of the evaluation objects do not meet the model assumptions, which may cause the valuation results to deviate from the actual value. For example, a multi-period binary tree is not applicable to all companies. Its theoretical basis is that the underlying asset and risk-free loan assets can construct an equivalent asset portfolio. Whereas, when the underlying asset does not have an active trading market or cannot be traded, the conditions for the establishment of option pricing theory Not enough. Moreover, the traditional BS pricing model is based on the evaluation of the value of corporate mergers and acquisitions under complete information, but the market is often not fully effective and cannot reflect all information. Therefore, the pricing model of growth options under incomplete information is introduced, and it is found that incomplete information is useful for 
enterprises. The value of mergers and acquisitions has a significant impact. Moreover, the expiration time of real options is long and uncertain, and the risk-free interest rate may also change. In addition, market uncertainty will lead to changes in the value of patent assets (the value of the underlying asset), changes in the cost of raw materials, and in turn, changes in the investment cost (execution price). These indicators increase the uncertainty of asset valuation. Moreover, the traditional BS model assumes that volatility is a constant and asset prices follow a log-normal distribution. Nevertheless, for actual options, there is often a so-called "volatility smile" between the implied volatility and the exercise price. U-shaped curve without considering the impact of unexpected events on asset price fluctuations

\subsection{Market effectiveness needs to be improved}

Compared with traditional valuation methods, although the real option method has many advantages, traditional valuation methods are still preferred when asset appraisal agencies conduct asset appraisal business. There may be two reasons for this situation: one is that the capital market is still not effective enough, resulting in the parameters in the model cannot be obtained from the market, which limits the application of the model; the other is that the appraisal professionals are not very familiar with the concept of options and there are many kinds of theory and real option pricing models, and a lot of mathematical knowledge needs to be used in the pricing process, which also increases the difficulty of understanding and applying the real option method in practice.

\section{Future research and outlook}

The research on asset pricing based on the real option method is a long-term and dynamic process. In the research process, the principle of combining theory and practice should be adhered to optimize the real option method pricing model and improve the practicability of the model. For this reason, the future research of real option law can focus on the following aspects.

\subsection{Further research on compound option pricing research model}

Considering uncertainty and complexity in economic development, many underlying assets will have multi-stage and multi-type real options. At this time, the real option value of the appraisal object is not a simple sum of the values of multiple real options, and may exist Value synergy or value offset phenomenon. Taking the complexity of the interaction between options and the cumbersome derivation of model formulas into account, scholars should proceed from the actual situation to derive a more representative and practical compound option pricing model.

\subsection{Explore the combined use of the real option method and other theories}

In the process of using the real option method for valuation, many scholars have tried to combine this method with many other theories for research. These theories include game theory, life cycle theory, principal-agent theory, prospect theory, etc. Through more detailed analysis, the valuation results are more accurate and reliable, and closer to the true value of the underlying assets. In the future academic research and practical research, we should still pay attention to the combination of real options and other theories to improve the scope of application of real options.

\subsection{Expand the field of real option pricing}

In the existing research, the real option method pricing research involves almost all walks of life, but new things and their evaluation areas will continue to emerge, e.g., the rise of $5 \mathrm{G}$ technology. These emerging things will have an important impact on economic development and have strong uncertainty. The path to fairly use the real option method to value assets in emerging fields to help stakeholders make investment and financing decisions remains to be further studied.

\subsection{Achieve smart pricing by using Internet technology}

Considering the complexity of real option method model calculations, computer programming techniques can be used to input model formulas, verify the calculation results, and use Internet big data to collect, sort and measure corresponding model parameters to make the real option method pricing process simpler and more efficient.

It should be noted that the real option method is not a denial of traditional valuation methods, but an effective supplement to traditional methods. This method should be used fairly under applicable conditions, rather than blindly applying pricing models. Only by using this method correctly can the value of the target asset be evaluated scientifically and fairly, and a reliable value reference can be provided for decision-making.

\section{CONCLUSION}

In summary, this article summarizes the research progress of applying the real option method to project valuation and reveals the current development status of real options. Specifically, it explores the advantages of real options over DCF valuation methods through relevant academic research and summarizes the models 
for project valuation using real options: binary tree model and trigeminal tree model, BS model and Geske model, stochastic differential equation method, and Monte Carlo simulation method. Afterwards, it summarizes the estimation of the specific parameters of the real option model and analyzes the valuation methods of the underlying asset value, execution price, exercise period, volatility, and risk-free interest rate. This article then discusses the difficulties and existing problems in the application of real options, and finally puts forward the relevant prospects for the research direction of real options.

In the future, regarding the valuation research of real option models, scholars will add more reference variables to the model to analyze multi-stage and multi-type real options, i.e., enhancement the real options applicability to more types of company value research. Moreover, the computing power in artificial intelligence can also be used in the research of real options, and more accurate results can be obtained by performing more calculations. This makes the valuation framework of real options more advanced. Overall, these results offer a guideline for more accurate asset pricing model by real option methodlogy and pave a path for wider application of the methodlogy

\section{REFERENCES}

[1] Myers Stewart C.(1977).Determinants of corporate borrowing. doi:10.1016/0304-405X(77)90015-0.

[2] Ashok Banerjee.(2003).Real Option Valuation of a Pharmaceutical Company. Vikalpa: The Journal for Decision Makers(2), doi:10.1177/0256090920030205.

[3] Kuangyuan Zhang,Antonio Nieto \& Andrew N. Kleit.(2015).The real option value of mining operations using mean-reverting commodity prices. Mineral Economics(1), doi:10.1007/s13563-014-0048-6.

[4] Sudi Sudarsanam,Ghulam Sorwar \& Bernard Marr.(2006).Real options and the impact of intellectual capital on corporate value. Journal of Intellectual

Capital(3), doi:10.1108/14691930610681410.

[5] Cox John C.,Ross Stephen A. \& Rubinstein Mark.(1979).Option pricing: A simplified approach. (3), doi:10.1016/0304-405X(79)90015-1.

[6] Boyle Phelim P..(1977).Options: A Monte Carlo approach. doi:10.1016/0304-405X(77)90005-8.

[7] Edward Omberg.(1988).Efficient Discrete Time Jump Process Models in Option Pricing. Journal of Financial and Quantitative Analysis(2), doi: $10.2307 / 2330879$.

[8] Yisong Tian.(1993).A modified lattice approach to option pricing. (5), doi:10.1002/fut.3990130509.

[9] Titman, S. (1985). Urban Land Prices Under Uncertainty. The American Economic Review, 75(3), 505-514. Retrieved September 3, 2021, from http://www.jstor.org/stable/1814815

[10] David Kellogg \& John M. Charnes.(2000).Real-Options Valuation for a Biotechnology Company. Financial Analysts Journal(3), doi: 10.2469/faj.v56.n3.2362

[11] Robert Geske.(1977).The Valuation of Corporate Liabilities as Compound Options. Journal of Financial and Quantitative Analysis(4), doi: $10.2307 / 2330330$.

[12] Geske, R., \& Johnson, H. (1984). The Valuation of Corporate Liabilities as Compound Options: A Correction. The Journal of Financial and Quantitative Analysis, 19(2), 231-232. doi: $10.2307 / 2330900$

[13] Hélyette Geman,Nicole El Karoui \& Jean-Charles Rochet.(1995).Changes of numéraire, changes of probability measure and option pricing. Journal of Applied doi:10.1017/S002190020010289X.

[14] Eduardo S. Schwartz \& Mark Moon.(2001).Rational Pricing of Internet Companies Revisited. Financial Review(4), doi:10.1111/j.1540-6288.2001.tb00027.x.

[15] Richard Ebil Ottoo.(2018).Valuation of Corporate Innovation and the Pricing of Risk in the Biopharmaceutical Industry: The Case of Gilead. Journal of Applied Corporate Finance(2), doi:10.1111/jacf.12303.

[16] Eduardo S. Schwartz \& Mark Moon.(2001).Rational Pricing of Internet Companies Revisited. Financial Review(4), doi:10.1111/j.1540-6288.2001.tb00027.x.

[17] Francis A. Longstaff \& Eduardo S. Schwartz.(2001).Valuing American Options by Simulation: A Simple Least-Squares Approach. The Review of Financial Studies(1), doi: $10.1093 / \mathrm{rfs} / 14.1 .113$

[18] Brian J Hall \& Kevin J Murphy.(2000).Optimal Exercise Prices for Executive Stock Options. American Economic Review(2), doi:10.1257/aer.90.2.209.

[19] Majewska, A. (2015). The formula of exercise price in employee stock options-testing of the proposed approach. Prace Naukowe Uniwersytetu 
Ekonomicznego we Wrocławiu, (381), 211-221. doi: $10.15611 / \mathrm{pn} .2015 .381 .16$

[20] Fischer Black \& Myron Scholes.(1973).The Pricing of Options and Corporate Liabilities. (3), doi:10.1086/260062.

[21] Vasicek Oldrich.(1977).An equilibrium characterization of the term structure. (2), doi:10.1016/0304-405X(77)90016-2.

[22] Cox, J., Ingersoll, J., \& Ross, S. (1985). An Intertemporal General Equilibrium Model of Asset Prices. Econometrica, 53(2), 363-384. doi:10.2307/1911241 